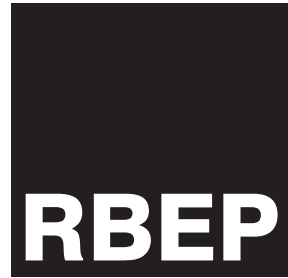

\section{Juventude e transição para o ensino médio: desafios e projetos de futuro}

\author{
Elodia Honse Lebourg ${ }^{\mathrm{I}, \mathrm{II}}$ \\ Rosa Maria da Exaltação Coutrim ${ }^{\text {III,IV }}$ \\ Luciano Campos da Silva ${ }^{\mathrm{V}, \mathrm{VI}}$
}

https://doi.org/10.24109/2176-6681.rbep.102.i260.4149

\section{Resumo}

Para contribuir para o debate sobre a chegada dos jovens ao ensino médio, esta pesquisa analisou um grupo de estudantes de um distrito que, após a conclusão do ensino fundamental na escola local, passou a estudar na sede do município. Para compreender como percebiam seus processos de transição para o ensino médio, a pesquisa de campo foi realizada com base em entrevistas reflexivas com oito jovens e o material gerado foi analisado por meio de perfis de configuração com informações organizadas individualmente. Constatou-se que a transição para o ensino médio, especialmente para jovens do interior, é um momento no qual se amplia a rede de sociabilidade e surgem complexos desafios. Espera-se que os resultados da pesquisa contribuam para as discussões sobre os sentidos do ensino médio para jovens das camadas populares, sobretudo associados ao que planejam para o futuro.

Palavras-chave: ensino médio; juventude; transição para a vida adulta.

\footnotetext{
Universidade Federal de Ouro Preto (Ufop). Ouro Preto, Minas Gerais, Brasil. E-mail: <ehlebourg@yahoo. com.br $>$; <https://orcid. org/0000-0001-8521-0389>.

II Mestre em Educação pela Universidade Federal de Ouro Preto (Ufop). Ouro Preto, Minas Gerais, Brasil.

III Universidade Federal de Ouro Preto (Ufop). Ouro Preto, Minas Gerais, Brasil. E-mail: <rosacoutrim@ufop. edu.br >; <https://orcid. org/0000-0002-9510-1263>.

Iv Doutora em Sociologia e Política pela Universidade Federal de Minas Gerais (UFMG). Belo Horizonte, Minas Gerais, Brasil.

v Universidade Federal de Ouro Preto (Ufop). Ouro Preto, Minas Gerais, Brasil. e-mail: <lucianocampos @ufop.edu. br >; <https://orcid. org/0000-0001-9717-8558>.

vI Doutor em Educação pela Universidade Federal de Minas Gerais (UFMG). Belo Horizonte, Minas Gerais, Brasil.
} 


\section{Abstract \\ Youth and transition to High School: challenges and projects for the future}

In order to add to the debate on the arrival of teenagers at high school, this research analyzes a group of students from a district initiating their studies at the seat of the municipality upon finishing local Middle School. To comprehend how they perceived their transition process to high school, field research took as reference some reflexive interviews with eight teenagers and the resulting material was analyzed individually. Findings show that transitioning to high school, especially for teenagers from the rural areas, allows for the enlargement of their sociability networks, leading them to face new complex challenges. The authors hope that the results of this research contribute to the discussions on the significance of high school for low-income teenagers, particularly regarding their plans for their futures.

Keywords: coming of age; high school; youth.

\section{Resumen \\ Juventud y transición a la educación secundaria: desafíos y proyectos de futuro}

Para contribuir al debate sobre la llegada de los jóvenes a la educación secundaria, esta investigación analizó un grupo de estudiantes de una localidad que, después de concluir la educación primaria en la escuela local, empezó a estudiar en la sede municipal. Para comprender como percibían sus procesos de transición a la educación secundaria, la investigación de campo se realizó a partir de encuestas reflexivas con ocho jóvenes y el material generado se analizó por medio de perfiles de configuración con informaciones organizadas individualmente. Constatamos que la transición a la educación secundaria, especialmente para jóvenes del interior, es un momento en el cual se amplía la red de sociabilidad y surgen desafíos complejos. Se espera que los resultados de la investigación contribuyan a las discusiones sobre los significados de la educación secundaria a los jóvenes de las clases populares, sobre todo asociados con lo que planean para el futuro.

Palabras clave: educación secundaria; juventud; transición a la vida adulta. 


\section{Introdução}

A juventude é um período de inserção social e de experimentações e é nessa fase da vida que o indivíduo se capacita para se desenvolver como adulto. Assim, os jovens são sujeitos de múltiplas vivências do mundo, e a constituição da condição juvenil só pode ser compreendida com base nas relações sociais que eles estabelecem e nas configurações sociais nas quais se encontram inseridos, inclusive na escola (Camarano et al., 2004; Carrano, 2008).

No Brasil, existem mais de 47 milhões de jovens, de acordo com dados do Instituto Brasileiro de Geografia e Estatística (IBGE, 2019) e, atualmente, em todo o País, existem milhares de jovens cursando o ensino médio momento marcado por transformações na construção identitária, por maior autonomia pessoal e por uma nova relação com suas famílias, suas escolas, seus grupos de amigos e sua comunidade. Aqueles de camadas populares enfrentam, ainda, uma série de dificuldades de acesso e de permanência na escola durante esse período, além de, muitas vezes, ingressarem nesse nível de estudo com distorção idade/série em função de trajetórias escolares que contêm, em muitos casos, rupturas no processo e/ou reprovações.

Contribuindo para o debate sobre as juventudes em comunidades do interior do País, este artigo é resultado de uma pesquisa de mestrado ${ }^{1}$ que analisou a situação de jovens que mudaram de ambiente escolar e social para ingressarem no ensino médio. Tem como foco um grupo de estudantes de um pequeno distrito que, após a conclusão do ensino fundamental na única escola local, passou a estudar na sede do município. O distrito do qual esses jovens se originam possui pouco mais de 1.500 habitantes e traços interioranos e rurais.

Os jovens dessa comunidade experimentam, geralmente, duas dinâmicas distintas relacionadas à sua formação escolar e que repercutem em outros aspectos de suas vidas. Até o $9^{\circ}$ ano do ensino fundamental, quase todos estudam na escola distrital, que possui cerca de 150 estudantes matriculados entre a educação infantil e o ensino fundamental. Depois, para cursar o ensino médio, por volta dos 15 anos de idade, deslocam-se para a sede do município, distante cerca de 20 quilômetros do distrito, sendo que parte desse trecho não é asfaltado e que o transporte escolar somente é disponibilizado nos turnos da manhã e da noite. A maioria desses jovens, que estudaram juntos desde a infância, se divide, pela primeira vez, em três instituições públicas denominadas, neste estudo, de: Escola Estadual 1, Escola Estadual 2 (cujos critérios de admissão são a conclusão do ensino fundamental) e Escola Federal 1 (uma instituição federal que oferece cursos técnicos profissionalizantes, tem um processo de seleção concorrido e, no momento da pesquisa, atendia cerca de 1.600 estudantes).

A proposta da investigação foi, então, compreender como os jovens desse distrito, admitidos em escolas da sede do município, perceberam seus processos de transição para o ensino médio em um espaço prioritariamente urbano e diversificado cultural e socialmente. Nesse sentido, a pesquisa procurou responder às seguintes questões: como esses

\footnotetext{
LEBOURG, Elodia Honse. Delicadas travessias: um estudo de caso sobre jovens em transição para o ensino médio no interior do Brasil. Dissertação (Mestrado em Educação) - Universidade Federal de Ouro Preto 2015. A pesquisa teve o financiamento do Conselho Nacional de Desenvolvimento Científico e Tecnológico (CNPq) e da Coordenação de Aperfeiçoamento de Pessoal de Nível Superior (Capes).
} 
jovens perceberam suas variações de desempenho escolar, tanto cognitivo como comportamental, durante o período de transição para o ensino médio? Como alteraram seus processos de sociabilidade entre pares, dentro e fora da escola, após o ingresso no ensino médio? Como se relacionaram com os professores do ensino médio nessa fase de transição? Como as influências socioculturais adquiridas a partir do contato com novos indivíduos e espaços na sede do município se incorporaram ao seu comportamento?

A pesquisa de campo foi realizada por meio de entrevistas reflexivas com oito jovens que ingressaram em uma das três escolas selecionadas. Para o estudo, os jovens receberam nomes fictícios: Paulo, Laís, Poliana, Lara, Maria, Alice, Igor e Joaquim. À época, esses jovens tinham entre 15 e 20 anos de idade, a maioria pertencia a famílias de baixa renda e todos possuíam bom desempenho escolar no ensino fundamental.

O material produzido por meio de entrevistas semidiretivas realizadas com os jovens foi analisado com a elaboração de perfis de configuração nos quais as informações obtidas sobre cada jovem foram organizadas individualmente (Lahire, 1997). A análise dos perfis de configuração foi escolhida por se constituir em um gênero de escrita científica no qual não se pretende negligenciar a singularidade de cada situação, mas interpretar os dados obtidos por meio de uma orientação interpretativa definida, com a apresentação de fatos teoricamente construídos e a contextualização das informações fornecidas pelos interlocutores.

Ressalta-se que um importante desafio das pesquisas em Educação, e que se buscou atender neste trabalho, foi justamente o de articular as análises mais específicas (como as propostas por estudos de caso) aos marcos socializadores que atuam sobre eles e sobre os demais indivíduos inseridos no grupo estudado. Ao relacionar o particular ao geral, por meio da elaboração dos perfis de configuração, procurou-se refletir sobre relações, estruturas e marcos de influência, como as escolas, as famílias e os grupos de amigos, em busca de uma perspectiva de compreensão do fenômeno social de transição para o ensino médio, bem como das variações de comportamento entre os interlocutores (Charlot, 2006; Lahire, 2007). Esses perfis foram analisados com base nas seguintes categorias: trajetória escolar, sociabilidade entre pares, sociabilidade com professores, e constituição do sujeito.

\section{Ensino médio e projetos de futuro dos jovens das camadas populares}

Para analisar o modo como os jovens vivenciam a experiência de transição do ensino fundamental para o ensino médio, é preciso, inicialmente, compreender de que forma essa etapa de ensino se insere em suas vidas e o modo como ela se relaciona à construção de projetos de futuro, especialmente àqueles associados ao trabalho e ao prosseguimento dos estudos. 
Destaca-se que a legislação atual define o ensino médio como etapa conclusiva da educação básica, que visa prioritariamente à formação da cidadania e supera seu caráter estritamente propedêutico. Para Sposito e Galvão (2004), nas últimas décadas, o aumento do número de vagas no ensino médio pode ser visto como uma consequência da ampliação do ensino fundamental e da adoção de estratégias para a redução da defasagem idade/ série. No entanto, tais estratégias ainda estão longe de garantir o acesso e a permanência dos estudantes na escola até a conclusão do ensino médio.

Apesar do aumento do número de vagas nessa etapa, de acordo com dados do Resumo Técnico do Censo da Educação Básica de 2018 (Brasil. Inep, 2019), entre 2013 e 2018, o total de matrículas caiu 7,1\%, devido à redução das entradas provenientes do ensino fundamental (entre 2014 e 2018, as matrículas do $9^{\circ}$ ano tiveram queda de 8,3\%) e à melhoria do fluxo no ensino médio (cuja taxa de aprovação subiu 3,0\%, entre 2013 e 2017).

No século 21, o ensino médio passou a conhecer maior diversidade no perfil dos estudantes que nele ingressam e tem trabalhado com realidades juvenis que se diferenciam por suas condições de existência e perspectivas de futuro. Nessa direção, Kuenzer (2000) já ressaltava que, para muitos jovens, essa etapa da formação escolar deveria garantir, de forma eficiente, duas necessidades distintas, mas que nem sempre se verificam: acesso ao mercado de trabalho e continuidade dos estudos.

Mesmo assim, o ensino médio ainda tem se configurado, para muitos jovens, como uma etapa intermediária entre a educação fundamental e o desejo de cursar o ensino superior, independentemente de a totalidade das vagas oferecidas na fase seguinte ser insuficiente em relação à demanda e da impossibilidade de muitos deles serem aprovados em exames admissionais para a graduação.

O tempo do ensino médio, dividido em três anos no ensino propedêutico no Brasil, parece ser, especialmente para os jovens das camadas populares, acelerado, breve e intenso (Sposito; Galvão, 2004). Para muitos desses jovens, é preciso, ainda, enfrentar dificuldades de permanência na escola, como a oferta de conteúdos disciplinares formais e pouco atrativos e problemas com a criação de espaços de sociabilidade que valorizem sua cultura extraescolar. O que se constata hoje é que o ensino médio é um espaço privilegiado de diversidade, com potencialidade para a geração de conhecimento e para a expressão individual e coletiva. Contudo, o currículo estrito e o desconhecimento das culturas juvenis por parte de gestores, professores e pelo próprio sistema de ensino impedem que muitos estudantes se reconheçam na escola e se sintam parte dela (Tomazetti; Schlickmann, 2016), principalmente se forem de camadas populares. Resta a eles a busca pelo diploma, estimulada pela promessa de conquistar um lugar no mercado de trabalho que seja melhor do que aquele alcançado por seus pais.

Apesar das dificuldades enfrentadas, concluir o ensino médio representa, para esses jovens, o crescimento dessas oportunidades. A possibilidade de ingresso no mercado de trabalho e o êxito profissional ainda estão intimamente relacionados ao sucesso escolar. Assim, para os 
estudantes, o comportamento e a dedicação pessoal são as bases do bom desempenho escolar; todavia, quanto antes se começa a trabalhar, menor tende a ser o nível de escolaridade e menos qualificadas as vagas oferecidas.

No caso de jovens das camadas populares, a permanência e o sucesso escolar no ensino médio também podem ter relação com a existência de configurações familiares estáveis, nas quais são levados a adquirir estruturas particulares de ordenação do mundo. As disposições familiares consagram parte dos hábitos mentais, culturais e de vida dos filhos, o que pode repercutir diretamente nas práticas escolares e na formatação dos projetos de futuro. No caso de famílias das camadas populares, mesmo aquelas com baixo capital escolar, o bom desempenho dos filhos pode estar relacionado a um maior investimento dos pais em sua educação, por meio do diálogo e da reorganização dos papéis domésticos (Lahire, 1997).

Também para aqueles estudantes provenientes de camadas populares, a conclusão do ensino médio representa um momento significativo, uma vez que muitos passam a compor a geração mais escolarizada de suas famílias. No entanto, o término dessa etapa de estudos acarreta um impasse diante da falta de perspectivas, pelo menos em curto prazo, por ser a última fase de estudos e por trazer muitas incertezas sobre a futura participação do jovem no mercado de trabalho.

Apesar disso, tal insegurança não tira dos estudantes o interesse em vivenciar plenamente essa etapa da vida com seus pares. Para muitos jovens das camadas populares, diferentemente daqueles das camadas médias, que almejam experienciar uma nova etapa da juventude na universidade, o ensino médio coincide com a última possibilidade de vivenciarem a condição juvenil.

\section{Transição para o ensino médio: o que dizem os dados?}

Para discutir os processos de transição dos jovens para o ensino médio, no âmbito deste artigo, optou-se por analisar mais detidamente os casos de dois dos oito jovens entrevistados para a realização da pesquisa. Essa tentativa foi a de perceber como o ensino médio se relacionava com seus projetos de futuro e em que medida o esforço dispendido para estudar fora do distrito fazia sentido para eles. A opção por apresentar mais detalhadamente as escolhas desses dois jovens se deve ao fato de que, entre os participantes que compuseram a amostra, os dois tinham os projetos de futuro mais divergentes. Ainda que tenham cursado o ensino fundamental na mesma escola, no distrito onde moravam à época, suas trajetórias e histórias familiares também eram bastante particulares.

Alice morava em um sítio distante cerca de cinco quilômetros do distrito. Por isso, passou a infância e parte da adolescência afastada dos colegas quando não estava na escola. Filha mais velha, tinha dois irmãos que cursavam o ensino fundamental. Seus pais não chegaram a concluir essa etapa da escolarização. A mãe trabalhava eventualmente no distrito, como faxineira, e o pai era funcionário de um matadouro vizinho ao sítio 
onde moravam. Alice tinha 17 anos quando foi entrevistada e iniciou o ensino médio na Escola Estadual 2, onde estudou por poucos meses. Nesse primeiro momento, como a escola oferecia o $1^{\circ}$ ano do ensino médio à tarde e o transporte escolar não era ofertado nesse turno, ela havia se mudado para a casa de uma tia, próxima à escola. Pouco depois dessa mudança, sua mãe decidiu que ela deveria estudar em outra escola, no turno da manhã, para que voltasse a residir no sítio da família. Foi transferida, assim, para a Escola Estadual 1, onde terminou o $1^{\circ}$ ano e cursou o $1^{\circ}$ bimestre do $2^{\circ}$ ano. Depois, retornou à Escola Estadual 2 e concluiu o $2^{\circ}$ ano estudando à noite. Durante o desenvolvimento da pesquisa, ainda na Escola Estadual 2, cursava o $3^{\circ}$ ano. Ao longo de parte do $1^{\circ}$ ano e no $2^{\circ}$ ano, morou na sede do município, na casa da tia. No momento da entrevista, havia voltado a morar com os pais. Em parte do ensino médio, trabalhou como babá e havia começado a atuar como auxiliar de cozinha, aos finais de semana, em um restaurante do distrito. O ingresso no ensino médio alterou completamente a vida da jovem que, mesmo sem ser reprovada, estudou em quatro turmas diferentes, de duas escolas, em menos de três anos. De acordo com seu relato, seus projetos de futuro envolviam cursar cinco graduações: Gastronomia, Geologia, Odontologia, Nutrição e Artes Cênicas. Também tinha planos de se casar com o namorado tão logo fosse possível.

Igor morava no distrito e, por isso, tinha mais acesso a uma vivência com os amigos fora do horário escolar. Sua família era mais escolarizada que a de Alice. A mãe completou o ensino fundamental e era dona de casa. O pai fez cursos técnicos e trabalhava como encarregado de obras em uma cidade próxima. Sua irmã, assim como ele, estudava na Escola Federal 1, e seu irmão fazia faculdade de Engenharia da Computação em uma cidade vizinha, onde morava e trabalhava. Igor tinha 16 anos, cursava, à época da pesquisa, o $1^{\circ}$ ano do curso técnico em Metalurgia da Escola Federal 1 e ainda morava com a família no distrito. Não trabalhava e mantinha bom desempenho escolar, assim como no ensino fundamental. Parecia ter encontrado pares com os quais se identificava e que tinham ideias convergentes com as suas. Já estava formulando projetos de futuro relacionados ao ensino superior e ao trabalho. Desejava estudar Bioengenharia Metalúrgica em uma universidade francesa conveniada à Escola Federal 1 e pretendia, depois disso, retornar ao Brasil, onde desenvolveria próteses para o corpo humano. A época da entrevista, Igor namorava, mas não pensava em se casar.

\section{Os desafios encontrados no ensino médio}

Um primeiro aspecto a ser destacado nas experiências de transição para o ensino médio de Alice e Igor são os desafios que eles encontraram, especialmente nos momentos iniciais de ingresso nas novas escolas.

Seus relatos sobre o ensino médio, especialmente pelo fato de precisarem cursá-lo fora do espaço onde viveram até então, encontram-se repletos de menções sobre medo, sofrimento e transformações nem sempre positivas e que refletiam o desgaste provocado em suas vidas durante todo esse processo. 
A experiência de cursar o ensino médio parece ter sido bastante complexa e um ponto comum aos dois jovens foi sobre o quanto suas rotinas se alteraram após o início das aulas. Os entrevistados relataram que passaram a acordar mais cedo, por volta das cinco horas da manhã, e que ficavam mais tempo fora de casa e do distrito. Disseram que, por isso, sentiam-se "mais cansados e menos animados" para estudar.

Para Alice e Igor, bem como para o restante dos jovens entrevistados durante a pesquisa de campo, cursar o ensino médio gerou um misto de angústia e de excitação diante da descoberta de uma nova realidade que se descortinava. Tratava-se, ainda, de um processo solitário, porque as famílias não entendiam bem o que eles viviam, mas, ao mesmo tempo, coletivo, uma vez que tinham colegas que passavam pela mesma situação.

Após o ingresso no ensino médio, cada um dos estudantes ouvidos passou por um processo de transição particular e desenvolveu uma relação específica com suas escolas, com a cidade e com as novas experiências vividas, como observado em outros estudos sobre a juventude brasileira (Carrano, 2008; Carrano; Marinho; Oliveira, 2015; Pais; Cairns; Pappámikail, 2005; Pais; Castilho, 2019). Acostumados a viver em um local pequeno e tranquilo, no qual, conforme mencionaram, "todo mundo conhecia todo mundo", o novo período inaugurou uma fase de transformações e conflitos que repercutiram nos seus desempenhos escolares, nos seus laços de sociabilidade e na modificação de suas personalidades (Reis; Dayrell, 2020). Dessa forma, antigas práticas foram deixadas de lado, como se quisessem modificar sua personalidade diante de um novo contex to de maior liberdade. Apesar disso, sentiam-se despreparados perante tantas transformações e passaram a ter de enfrentar novos desafios e medos. Igor (16 anos, $1^{\circ}$ ano), por exemplo, relatou: "querendo ou não, em todo o meu período acadêmico, estudei sempre com quem conhecia. E chegar aqui, numa sala bem maior do que antes, com pessoas praticamente desconhecidas, acho que foi um choque muito grande".

Para esses jovens, a opção pelas novas escolas e, no caso de Igor, pelo curso técnico, apresentou-se carregada de insegurança quanto à decisão sobre seu futuro e ao sentido imediato do investimento escolar. Ainda assim, é importante considerar que o esforço para permanecer na escola, especialmente porque a transição para o ensino médio acarretava o deslocamento geográfico e o enfrentamento dos desafios decorrentes dessa mudança, estava sendo considerado prioritariamente como uma medida para aumentar as chances de acesso ao mercado de trabalho por meio da diplomação, assim como já constatado por Dayrell (2012) e Zago (2012) em seus estudos. A esse respeito, Igor demonstrava, aparentemente, mais preocupação com o futuro que Alice. Talvez por cursar uma escola técnica, sua fala foi constantemente marcada por afirmações, como:

\footnotetext{
acho que fiquei muito mais experiente, sabe? Deixei de ser um pouco criança e, na hora que eu vim para cá [Escola Federal 1], acho que tive de encarar as coisas com mais maturidade. Eu acho que mudei também na parte de fala, porque, aqui, em todo momento, na área de Português, você é orientado sobre a questão da locução. Os nossos professores
} 
técnicos falam sempre: "vocês têm de saber conversar, porque, daqui a um tempo, vocês serão profissionais, estarão apresentando projetos, então não podem chegar lá e falar de qualquer jeito" (Igor, 16 anos, $1^{\mathrm{o}}$ ano).

Nas novas escolas, tanto Alice como Igor encontraram uma série de dificuldades de adaptação. O ensino em tempo integral na Escola Federal 1, a alteração dos horários para acordar e para se alimentar, a necessidade de sempre portar dinheiro, de estar longe de casa e da família, e de se relacionar com pessoas desconhecidas parecem ter sido fatores que provocaram angústia e medo após o ingresso no ensino médio. Seus comentários acerca dos primeiros dias de aula na sede foram diversificados e envolveram relatos de insegurança, medo, euforia e encantamento. Alice contou que seus primeiros dias de aula no ensino médio, na Escola Estadual 2, foram "muito, muito, muito bons". Também comentou que ela e os novos colegas estavam "muito emocionados", porque ninguém havia estudado no $1^{\circ}$ ano até aquele momento e tinham vontade de "saber tudo, conhecer tudo, fazer de tudo". A jovem completou: "eu gosto de mudança, eu até achei legal. Tipo assim, todo adolescente gosta de experimentar de tudo. Eu quero saber como é" (Alice, 17 anos, $3^{\circ}$ ano).

A escola, mais que a cidade, parecia representar o "novo" na vida desses jovens e foi nela que suas novas relações sociais se estabeleceram. Alice e Igor iam a outros lugares, onde faziam cursos ou atividades físicas, mas suas escolas continuaram sendo o principal espaço da sede do município no qual permaneciam. Seus novos colegas de turma passaram a formar importante porção dos seus grupos de pares. As principais influências socioculturais com as quais passaram a ter contato estavam dentro das instituições escolares.

De acordo com Dayrell (1996), na escola, o comportamento dos estudantes se relaciona diretamente à sua cultura, às suas experiências anteriores e às suas expectativas com relação ao ambiente. Isso também pode ser verificado no caso dos jovens entrevistados, uma vez que sua cultura e suas experiências anteriores se referiam à época na qual estudavam na escola do distrito, onde eles e os demais colegas apresentavam um comportamento mais calmo e mais disciplinado. No ensino médio, Alice e Igor mencionaram que não alteraram significativamente a forma como se comportavam com relação ao ensino fundamental. De acordo com seus relatos, continuavam sendo disciplinados e, a esse respeito, Alice mencionou: "eu fico tranquila na sala, sempre que o professor pede, eu faço. Nunca discuto com o professor. O professor, para mim, sempre tem razão. Melhor não bater boca" (Alice, 17 anos, $3^{\circ}$ ano).

As dificuldades vivenciadas pelos jovens também passaram pela relação com os professores, mais numerosos e com tratamento impessoal. Alice e Igor observaram que sua relação com os docentes do ensino médio estava sendo muito diferente daquela que tinham na escola distrital. Os estudantes se referiram a professores pouco interessados e desestimulados em função do convívio difícil com "alunos malandros", conforme constatou Alice. Além disso, percebiam que os estudantes oriundos dos distritos eram 
tratados como grupo, sem que houvesse uma preocupação maior com suas individualidades e sua adaptação. Eram considerados os "estudantes do distrito X". Havia, portanto, por parte desses professores, "a perpetuação de uma identidade grupal que se sobrepunha à identidade individual" (Lebourg; Coutrim, 2018, p. 620), e isso os incomodava.

O espaço da escola e o seu entorno também se apresentaram, para esses jovens, como um desafio em suas vidas. Conforme relatou Igor (16 anos, $1^{\circ}$ ano): "a gente não estava acostumado a estudar numa sala de aula ouvindo barulho de carro, barulho de buzina. No começo, atrapalhou um pouco a adaptação do trânsito também em volta do campus". Tais mudanças, no entanto, não parecem ter impactado negativamente o jovem, provavelmente por seu caráter de novidade. Por sua vez, no período em que estudou na Escola Estadual 2, Alice (17 anos, $3^{\circ}$ ano), que, nesse momento, morava no sítio da família, contou que gostava da localização de sua escola, em um bairro movimentado da cidade: "ali perto, quando a gente ia sair da escola, tinha alguma coisa para comprar, não precisava ficar andando em morro, não precisava de nada. Era tudo muito acessível, pertinho. Era bom".

Apesar de toda dificuldade, a escola continuou sendo percebida como um espaço privilegiado de socialização (Reis, 2019) e tanto Alice como Igor mencionaram que, com o tempo, o contato com os novos amigos e colegas melhorou sua rotina escolar e amenizou o estranhamento acarretado pelas mudanças advindas do ingresso no ensino médio.

Nos relatos de Alice, de Igor e dos outros seis jovens entrevistados durante a pesquisa, é possível perceber aspectos comuns em suas experiências, mas é importante ressaltar que, após o ingresso no ensino médio, esses jovens assumiram formas singulares de viver sua condição juvenil. De maneira geral, alteraram seu desempenho escolar, seus laços de sociabilidade e seu comportamento. Em suas travessias pelo ensino médio, cheias de sofrimento e de novidades, transformaram suas formas de ver e de agir diante do mundo e começaram a planejar seus futuros (Lebourg; Coutrim, 2018).

\section{Projetos de futuro: casamento, faculdade e trabalho}

Outro aspecto a ser destacado com base na análise das experiências dos jovens investigados são os seus projetos de futuro, especialmente em relação ao casamento, ao mundo do trabalho e ao prosseguimento dos estudos.

Alguns autores chamam a atenção para a importância da escola como uma das promotoras da inserção juvenil no universo profissional e na vida adulta. A escola, segundo eles, deveria ser capaz de buscar construir processos de aprendizagem e mecanismos de participação, de promover cidadania e de preparar os estudantes para o ingresso no mercado de trabalho (Camarano et al., 2004; Charlot, 2009; Dayrell; Gomes; Leão, 2010). Considerando que seis dos oito jovens entrevistados já trabalhavam (as exceções eram Igor e Joaquim) no momento em que a pesquisa de campo 
foi realizada, quase todos informalmente, fazendo pequenos serviços esporádicos e sem registro trabalhista, em áreas que não se relacionavam com os conteúdos curriculares estudados no ensino médio, parece que o intento de os preparar para o mercado de trabalho não estava sendo exitoso.

De acordo com Dayrell (2012, p. 313), uma parcela significativa dos jovens só é capaz de vivenciar sua condição juvenil devido ao trabalho, responsável por garantir os recursos para o consumo, o lazer e o namoro, além da ampliação da rede de relações: "enquanto experiência individual, o trabalho aparece numa dupla dimensão: uma relação de maior autonomia com a família e, ao mesmo tempo, a possibilidade de vivenciar a própria condição juvenil". Os relatos dos seis jovens entrevistados que já trabalhavam à época do ensino médio, o que incluía Alice, abordavam justamente a necessidade de obter algum tipo de renda para custear pelo menos parte de suas despesas individuais, como a compra de roupas e o pagamento de cursos e academias. Além disso, observou-se que a maioria optou por trabalhos com carga horária reduzida e concentrada aos finais de semana, para que não atrapalhasse a dedicação aos estudos e não comprometesse as idas diárias para suas escolas na sede do município.

Procurando garantir certa autonomia diante de sua vida, Alice trabalhava informalmente como auxiliar de cozinha e já havia trabalhado como babá. No momento da entrevista, a jovem contou que ia investir parte de sua remuneração em mensalidades de aulas de dança do ventre, curso que frequentava na sede do município. Igor, por sua vez, relatou que ainda não trabalhava, porque o pai conseguia manter financeiramente a família.

Assim como o ingresso, a conclusão do ensino médio também estava sendo um momento complexo para os jovens do distrito. Isso acontecia, entre outros fatores, pela necessidade de definirem como empregariam seu tempo após a finalização dos estudos. Nessa direção, a pesquisa de Coutrim, Cunha e Matos (2016) revela que a rede de socialização formada pela família, pelos professores, pelos namorados e pelos amigos tem grande influência na decisão sobre continuar os estudos, ingressar no ensino superior ou fazer uma escolha profissional. Isso pode ser observado no caso de Alice, cujos pais, mesmo com dificuldade, acompanharam todo o seu processo de escolarização durante o ensino médio. A família de Igor, ao sustentar as despesas do filho e não necessitar que ele trabalhasse durante essa etapa de estudos, também pode ter contribuído para a elaboração dos seus projetos de futuro.

A literatura já tem discutido a questão do trabalho para os jovens de baixa renda e vem revelando que, mesmo após a conclusão do ensino médio, a inserção dos jovens de camadas populares no mercado de trabalho é incerta (Carrano, 2008; Carrano; Marinho; Oliveira, 2015; Costa; Koslinski, 2006; Kuenzer, 2000). Alice, ao trabalhar como auxiliar de cozinha em um restaurante do distrito aos finais de semana, já estava ocupando uma vaga de trabalho informal e precária, que provavelmente não lhe permitiria iniciar, ou mesmo progredir, em uma carreira profissional.

Acompanhando a recente ampliação das oportunidades de acesso ao ensino superior, Alice e Igor desejavam dar continuidade aos estudos 
visando ao aprendizado de uma profissão. As escolhas de Alice com relação à graduação são curiosas, pois relatou que desejava cursar cinco faculdades.

Eu quero estudar Gastronomia e Geologia. Primeiro, vou aprofundar na Gastronomia. Depois de me formar, vou fazer Geologia. Aí pretendo fazer Odontologia. Depois quero fazer Nutrição. Eu sei que é muita coisa! Depois, quem sabe, eu faço Artes Cênicas. Eu vou passar a minha vida toda estudando. [riso] [...] Em Gastronomia, quero estudar o básico. Depois quero sair do Brasil, profissionalizar mesmo, sabe? [...] Primeiro, tenho de conseguir dinheiro para pagar a universidade, porque a universidade de Odontologia é só particular, no Rio [Rio de Janeiro-RJ]. [...] As mais próximas tem de pagar. Mas tipo, lá no Rio, eu acho interessante e é perto da casa dos meus primos, aí já é, tipo, mais fácil. [...] Eu sei que é muita coisa, mas, primeiro, vou na coisa que eu gosto, depois em uma coisa que acho interessante. Quem sabe eu, sendo uma geóloga lá nos Estados Unidos, que nem aquele filme, 2012, não salvo a minha família? [riso]. Depois vou fazer Odontologia que eu acho maior interessante [sic], ganha bem. E depois uma coisa prática e simples, que é Artes Cênicas, que também é muito legal, eu gosto muito, mas que não vai me dar um futuro (Alice, 17 anos, $3^{\circ}$ ano).

Ainda sobre seus projetos de futuro, Alice contou que namorava um rapaz mais velho que ela, morador de um bairro periférico da sede do município, e que trabalhava em uma das mineradoras da região. Segundo ela, o namorado já fazia planos de se casar. A esse respeito, a jovem comentou que "em um futuro não tão distante" seria possível que se casasse com ele, mesmo que os dois precisassem morar "não sei onde". O namoro parece ter limitado a vida social da jovem, porque, depois de iniciá-lo, ela relatou que só saía para se divertir na companhia do namorado e que, quando ele não podia ir ao distrito para encontrá-la, ficava em casa. Além disso, em 2014, Alice havia encerrado sua conta no Facebook a pedido do rapaz. Mesmo sendo, segundo suas palavras, "viciadaça" na rede social, acreditava que a decisão havia contribuído para evitar conflitos, uma vez que o namorado era ciumento: "tipo, saiu o Facebook e meu namorado entrou no lugar. Ele ocupa o espaço que ficou vazio do Facebook. É melhor, eu acho" (Alice, 17 anos, $3^{\circ}$ ano).

Por sua vez, Igor informou que pretendia se graduar na área de Bioengenharia Metalúrgica na França para, em seguida, trabalhar no ramo de próteses para o corpo humano. Seu interesse pelo tema surgiu na Escola Federal 1, onde participou de uma pesquisa na qual haviam constatado que a maioria das próteses feitas para o corpo era pesada e difícil de manejar. Estava fazendo, desde então, projetos de estudos com metais e ligas metálicas que pudessem facilitar a movimentação de circuitos robóticos. Igor comentou que, por isso, pretendia expandir as pesquisas nessa área em um centro de estudos francês: "pelo que me 'antenei', é bacana lá. Ensino de qualidade e os melhores profissionais dessa área são de lá". Se aprovado nessa faculdade, contou que passaria por um período de adaptação na França no qual aprenderia o idioma. No momento da entrevista, Igor tinha 16 anos e namorava, mas contou que ainda não pensava em se casar.

Nesse sentido, é interessante observar que, mesmo quando Igor relatou que queria se graduar na França, a narrativa sobre seu projeto parecia 
mais exequível que a de Alice. A jovem, ao mencionar a possibilidade de estudar em cinco cursos superiores, em alguns casos inspirada por cenas que via pela televisão, parecia não ter uma noção aproximada do que seria cursar uma graduação.

Em um levantamento informal, realizado cerca de dois anos após a conclusão do trabalho de campo, verificou-se que as expectativas dos jovens se diferenciaram bastante daquilo que relataram a respeito de seus projetos de futuro e, em ambos os casos, se distanciaram daquilo que haviam estudado durante o ensino médio. Alice contou que havia tentado o vestibular para Gastronomia, curso de graduação oferecido pela Escola Federal 1, mas não havia sido aprovada. A jovem estava estudando no curso técnico em Edificações oferecido pela Escola Federal 1, na sede do município, mas ainda não sabia com o que pretendia trabalhar, uma vez que, segundo ela, não se identificava com o que estava estudando. Ao contrário do que havia mencionado durante a entrevista, ainda não havia se casado com o namorado.

Igor, por sua vez, havia concluído o ensino médio e também tinha alterado seus planos. Informou que estava cursando graduação em Administração, em uma universidade pública federal. Para poder se dedicar mais aos estudos, oferecidos no turno da noite, o jovem havia se mudado da casa dos pais para uma república estudantil localizada na sede do município. Também havia terminado o namoro que manteve durante parte do ensino médio.

Os projetos de futuro de Alice e Igor não se diferenciavam daquilo desejado, geralmente, por outros jovens e envolviam, basicamente, a continuidade dos estudos no ensino superior, a possibilidade de ter um bom emprego e o casamento (no caso, somente para Alice). Existia a possibilidade de que, logo, Alice parasse completamente de estudar, pois ainda não havia conseguido ingressar no ensino superior e frequentava um curso técnico somente para "ganhar tempo", segundo suas palavras. Tampouco, havia segurança sobre a possibilidade imediata de seguirem uma profissão. Mesmo Igor, que concluiu o curso técnico em Metalurgia, não pensava em trabalhar nesse campo e passou, em seguida, a cursar uma graduação em área diferente de sua formação anterior.

O final do ensino médio é uma incógnita para muitos jovens, especialmente os oriundos de camadas populares, o que inclui Alice e Igor. Sua conclusão não garante a continuidade dos estudos, mas revela a possibilidade de um novo momento de incertezas e medo prestes a chegar.

\section{Considerações finais}

A chegada ao ensino médio no Brasil ainda não é para todos. São excluídos dessa etapa de ensino muitos jovens que estudam em zona rural e que não têm escolas próximas às suas casas, que são trabalhadores, que já constituíram família, que estão à margem da lei ou privados de liberdade, entre tantos outros. Neste estudo, a proposta foi conhecer um pouco da 
vida dos jovens moradores de um pequeno distrito que, diferentemente de seus pais e de outros amigos, partiram em busca do diploma do ensino médio, mesmo que isso implicasse grande mudança nas suas rotinas diárias, no círculo de relacionamentos, no ritmo de estudos etc. Procurou-se, ao escutar esses jovens, compreender como perceberam seus processos de transição para o ensino médio em um espaço prioritariamente urbano e diversificado cultural e socialmente.

Os principais resultados deste estudo evidenciam que, à medida que percorreram as etapas da formação escolar, os estudantes passaram por processos diversos de amadurecimento e de experimentação de projetos presentes e futuros relacionados à sua vivência pessoal, profissional e escolar. Certamente, amadureceram com a transição para o ensino médio, mas o saudosismo manifestado, associado à infância no distrito, à escola, aos professores, aos colegas e aos amigos da época em que ainda cursavam o ensino fundamental, mostrou a dificuldade desse processo. Esses jovens viveram experiências positivas nesse período, como a oportunidade de fazerem novas amizades, os namoros e a possibilidade de fazerem aulas de dança. Apesar disso, o novo, a maior liberdade e a sociabilidade intensa parecem ter se tornado menos atraentes em função da exigência e do esforço para se adaptarem a essa nova etapa. A impessoalidade das relações, a reorganização da rotina e o cansaço foram pontos negativos que, para muitos, não superaram os atrativos da descoberta e da urgência de viver.

Mesmo diante das dificuldades de adaptação decorrentes da transição para o ensino médio em escolas fora do distrito, esses jovens não desistiram dos estudos. Desenvolveram projetos de futuro e reconheciam que, para que se concretizassem, continuar a estudar era fundamental. Para minimizar o impacto das mudanças e auxiliá-los nesse processo, o trabalho, as novas formas de se relacionar com a família, com os amigos e consigo foram fundamentais.

Apesar disso, embora se reconheça que o nível de escolaridade entre os jovens brasileiros esteja aumentando nos últimos anos, o ensino médio está enfrentando uma crise evidenciada pela falta de correlação entre seus princípios e objetivos. Indaga-se, dessa forma, a respeito da contribuição dessa etapa para a vida e para a constituição dos projetos de futuro dos jovens (Coutrim; Cunha; Matos, 2016; Sposito, 2003).

Ainda que poucos estudantes do distrito não tenham dado continuidade aos estudos depois da conclusão do ensino fundamental e que outros o tenham abandonado após o ingresso no ensino médio, a maioria dos jovens continuou estudando. Sem compreenderem exatamente o sentido daquilo que aprendiam na escola, a transição para o ensino médio representou um momento crítico para esses jovens que, limitados pelo seu local de origem, muitas vezes, tinham dificuldades para articular seus projetos de futuro. Mesmo assim, faziam muitos planos - casar, fazer curso de dança do ventre, cursar faculdade, viajar etc. - que nem sempre incluíam a localidade de origem. Não foi possível saber se essas metas foram/serão alcançadas e, para muitos, o final dessa etapa de estudos pode ter representado o retorno definitivo ao distrito ou, ainda, como no caso de Alice, a manutenção de seu trabalho informal aos finais de semana. 
Portanto, acredita-se que esta pesquisa contribui para os estudos sobre juventude ao perceber a transição para o ensino médio, especialmente para jovens do interior brasileiro, como um momento complexo no qual se amplia a rede de sociabilidade e surgem novos desafios e problemas. Desses jovens é exigido que saibam se situar em um novo espaço, lidar com estímulos e realidades até então desconhecidos, fazer novas amizades e se relacionar de forma diferente com seus pares e seus professores. É um momento delicado de transição que merece, portanto, maior atenção por parte das famílias, das escolas e dos gestores públicos. Assim, os casos aqui analisados, embora singulares, não falam somente de si, mas podem revelar aspectos importantes da transição para o ensino médio vivenciados por milhares de jovens brasileiros, especialmente aqueles que habitam em regiões interioranas.

Em um momento no qual a reforma do ensino médio, aprovada em 2017, parece colocar em xeque a formação de milhares de jovens das camadas populares, faz-se ainda mais oportuno escutá-los para considerar suas necessidades e seus anseios com relação ao futuro. Novos estudos são primordiais a respeito da transição para o ensino médio e dos projetos de futuro de jovens moradores de locais pouco privilegiados pelas pesquisas em Educação no Brasil, como as regiões do interior do País, espaços pouco populosos e/ou que pressupõem deslocamento geográfico para a continuação da escolarização básica. Dessa forma, esta pesquisa ressalta a importância de novas análises que privilegiem, por exemplo, a forma como os jovens constroem seus projetos de futuro por meio de uma perspectiva longitudinal que acompanhe seus primeiros anos após a conclusão do ensino médio.

\section{Referências}

BRASIL. Instituto Nacional de Estudos e Pesquisas Educacionais Anísio Teixeira (Inep). Resumo técnico: Censo da Educação Básica 2018.

Brasília, 2019.

CAMARANO, A. A. et al. Caminhos para a vida adulta: as múltiplas trajetórias dos jovens brasileiros. Última Década, Santiago, v. 12, n. 21, p. 11-50, dez. 2004.

CARRANO, P. Identidades culturais juvenis e escolas: arenas de conflitos e possibilidades. In: MOREIRA, A. B.; CANDAU, V. M.

(Orgs.). Multiculturalismo: diferenças culturais e práticas pedagógicas. Petrópolis: Vozes, 2008. p. 182-211.

CARRANO, P. C. R.; MARINHO, A. C.; OLIVEIRA, V. N. M. Trajetórias truncadas, trabalho e futuro: jovens fora de série na escola pública de Ensino Médio. Educação e Pesquisa, São Paulo, v. 41, n. esp., p. 14391454, dez. 2015. 
CHARLOT, B. A pesquisa educacional entre conhecimentos, políticas e práticas: especificidades e desafios de uma área de saber. Revista Brasileira de Educação, Rio de Janeiro, v. 11, n. 31, p. 7-18, jan./abr. 2006.

CHARLOT, B. A escola e o trabalho dos alunos. Sísifo: Revista de Ciências da Educação, Lisboa, n. 10, p. 89-96, set./dez. 2009.

COSTA, M.; KOSLINSKI, M. C. Entre o mérito e a sorte: escola, presente e futuro na visão de estudantes do Ensino Fundamental do Rio de Janeiro. Revista Brasileira de Educação, Rio de Janeiro, v. 11, n. 31, p. 133-154, jan./abr. 2006.

COUTRIM, R. M. E.; CUNHA, M. A. A.; MATOS, D. A. S. A difícil transição: a participação da família na escolha profissional de jovens egressos do Ensino Médio. Revista da FAEEBA: Educação e Contemporaneidade, Salvador, v. 25, n. 47, p. 173-186, set./dez. 2016.

DAYRELL, J. A escola como espaço sociocultural. In: DAYRELL, J. (Org.). Múltiplos olhares sobre educação e cultura. Belo Horizonte: Ed. UFMG, 1996. p. 136-161.

DAYRELL, J. Juventude, socialização e escola. In: DAYRELL, J. et al. (Orgs.). Família, escola e juventude: olhares cruzados Brasil - Portugal. Belo Horizonte: Ed. UFMG, 2012. p. 298-321.

DAYRELL, J.; GOMES, N. L.; LEÃO, G. Escola e participação juvenil: é possível esse diálogo? Educar em Revista, Curitiba, n. 38, p. 237-252, set./dez. 2010.

INSTITUTO BRASILEIRO DE GEOGRAFIA E ESTATÍSTICA (IBGE). Pesquisa Nacional por Amostra de Domicílios Contínua 2018: educação. Rio de Janeiro: IBGE, 2019.

KUENZER, A. Z. O Ensino Médio agora é para a vida: entre o pretendido, o dito e o feito. Educação \& Sociedade, Campinas, v. 21, n. 70, p. 15-39, abr. 2000.

LAHIRE, B. Sucesso escolar nos meios populares: as razões do improvável. Tradução de Ramon Américo Vasques e Sonia Goldefeder. São Paulo: Ática, 1997.

LAHIRE, B. Infancia y adolescencia: de los tiempos de socialización sometidos a construcciones múltiples. Revista de Antropología Social, Madrid, n. 16, p. 21-38, 2007.

LEBOURG, E. H.; COUTRIM, R. M. E. "Eu não queria estar aqui": juventude, Ensino Médio e deslocamento. Educação \& Realidade, Porto Alegre, v. 43, n. 2, p. 609-627, abr./jun. 2018. 
PAIS, J. M.; CAIRNS, D.; PAPPÁMIKAIL, L. Jovens europeus: retrato da diversidade. Tempo Social: Revista de Sociologia da USP, São Paulo, v. 17, n. 2, p. 109-140, nov. 2005.

PAIS, J. M.; CASTILHO, R. Como cartografar a condição juvenil e o futuro dos jovens? Entrevista com José Machado Pais. In: DUARTE, A. J.; CAVALCANTE, C. V.; GUIMARÃES, V. O. S. (Orgs.). Juventude e educação na América Latina. São Carlos, SP: Pedro \& João, 2019. p. 309-320.

REIS, J. B. Experiências juvenis de individuação: socialização familiar e escolar em narrativas biográficas. Revista Educação em Questão, Natal, v. 57, n. 53, p. 1-25, jul./set. 2019.

REIS, J. B.; DAYRELL, J. Experiências juvenis contemporâneas: reflexões teóricas e metodológicas sobre socialização e individualização. Educação, Santa Maria, v. 45, p. 1-23, jan./dez. 2020.

SPOSITO, M. P. Os jovens no Brasil: desigualdades multiplicadas e novas demandas políticas. São Paulo: Ação Educativa, 2003.

SPOSITO, M. P.; GALVÃO, I. A experiência e as percepções de jovens na vida escolar na encruzilhada das aprendizagens: o conhecimento, a indisciplina, a violência. Perspectiva, Florianópolis, v. 22, n. 2, p. 345-380, jul./dez. 2004.

TOMAZETTI, E. M.; SCHLICKMANN, V. Escola, Ensino Médio e juventude: a massificação de um sistema e a busca de sentido. Educação e Pesquisa, São Paulo, v. 42, n. 2, p. 331-342, jun. 2016.

ZAGO, N. A relação escola-família nos meios populares: apontamentos de um itinerário de pesquisas. In: DAYRELL, J. et al. (Orgs.). Família, escola e juventude: olhares cruzados Brasil - Portugal. Belo Horizonte: Ed. UFMG, 2012. p. 132-150.

Recebido em 12 de fevereiro de 2020.

Aprovado em 14 de dezembro de 2020. 